\title{
PENGARUH E-CRM DAN SERVICE QUALITY TERHADAP CUSTOMER SATISFACTION DAN DAMPAKNYA TERHADAP CUSTOMER LOYALTY PADA PT XL
}

\author{
Marshellina; Hartiwi Prabowo \\ Management Department, School of Business Management, BINUS University \\ Jln. K. H. Syahdan No. 9, Palmerah, Jakarta Barat 11480 \\ Hartiwi2200@binus.ac.id
}

\begin{abstract}
This study aims to look at the influence and how much the influence of e-CRM (X1) and Quality of Service (X2) for Customer Satisfaction (Y) that impact on Customer Loyalty (Z) at PT XL. Data collection techniques were with questionnaires, the number of population in this study was approximately three million respondents, ie customers who use the product XL in West Jakarta, because the area most widely uses $X L$ provider. Total sample was 100 respondents and the technique used was simple random sampling. The method used in this study was Pearson correlation and path analysis. Based on the results of data analysis, structural equation is $Y=0.310+0.330 X 1+X 20.874$ and $Z=0.005 X 1+X 2+0.449-0.070+0.903 Y$, which Electronic Customer Relationship Management and the quality of service have yet to be effective in providing a positive influence for customer loyalty directly, but it must go through prior customer satisfaction as an intervening variable. Therefore, more companies should make improvements to the new way of communicating with customers via electronic media because it gives quite effective results for customer satisfaction in PT XL. In addition, PT XL should provide training and better development for the employees working in the company to improve the quality of service that can create customer loyalty.
\end{abstract}

Keywords: e-CRM, service quality, customer satisfaction, customer loyalty

\begin{abstract}
ABSTRAK
Penelitian ini bertujuan untuk melihat pengaruh dan seberapa besar pengaruh e-CRM $\left(X_{1}\right)$ dan Kualitas Pelayanan $\left(\mathrm{X}_{2}\right)$ terhadap Kepuasan Pelanggan (Y) yang berdampak pada Loyalitas Pelanggan $(\mathrm{Z})$ di PT XL. Teknik pengumpulan data dengan kuesioner, jumlah populasi dalam penelitian ini adalah sekitar tiga juta responden, yaitu pelanggan yang menggunakan produk XL di Jakarta Barat karena daerah ini paling banyak menggunakan provider XL. Jumlah sampel sebanyak 100 responden dan teknik yang digunakan adalah Simple Random sampling. Metode yang digunakan dalam penelitian ini adalah korelasi Pearson dan analisis jalur. Hasil analisis data, diperoleh persamaan struktural yaitu $Y=0,310 X 1+0,330 X 2+0,874$ dan $Z=0,005$ $X 1+-0,070 X 2+0,449 Y+0,903$, dengan Electronic Costumer Relationship Management dan kualitas pelayanan ternyata belum efektif dalam memberikan pengaruh positif bagi loyalitas pelanggan secara langsung, tetapi harus melalui kepuasan pelanggan terlebih dahulu sebagai variabel intervening. Oleh karena itu, sebaiknya perusahaan lebih melakukan peningkatan atas cara baru dalam berkomunikasi dengan pelanggan melalui media elektronik karena memberikan hasil yang cukup efektif terhadap kepuasan pelanggan di PT XL. Selain itu, PT XL harus memberikan pelatihan dan pengembangan yang lebih baik lagi bagi para karyawan yang bekerja di perusahaan untuk meningkatkan kualitas pelayanan yang dapat menciptakan loyalitas pelanggan.
\end{abstract}

Kata kunci: e-CRM, service quality, customer satisfaction, customer loyalty 


\section{PENDAHULUAN}

Pada dasarnya setiap perusahaan mempunyai tujuan yaitu mendapatkan keuntungan yang semaksimal mungkin namun terkadang perusahaan cenderung melupakan bahwa pelanggan merupakan salah satu aset yang berperan penting dalam membantu pencapaian tujuan tersebut. Setelah transaksi penjualan selesai, antara pembeli dan perusahaan tidak terjadi kontak. Hal itu membuat perusahaan kehilangan kesempatan untuk mendapat keuntungan yang lebih lanjut dari pembeli yang sama. Sesungguhnya persaingan saat ini lebih menekankan pada cara perusahaan dapat menyadari target utama yang menjadi sasaran dalam proses penjualan, pemasaran, dan pelayanan. Perusahaan dapat memperlakukan pelanggan dengan baik, melalui Customer Relationship Management (CRM), memungkinkan terciptanya kesetiaan pelanggan yang tidak hanya setia terhadap produknya saja tetapi juga setia pada perusahaan.

Penelitian Lai et al (2009) mengungkapkan bahwa penggunaan Internet sebagai saluran untuk perdagangan dan informasi memberikan kesempatan bagi bisnis untuk menggunakan Internet sebagai alat untuk manajemen hubungan pelanggan. Penelitian ini mengungkap hubungan antara e-CRM dan kepuasan pelanggan dengan menentukan adanya fitur e-CRM di situs web. e-CRM merupakan layanan dengan aplikasi berbasis web untuk menciptakan dan meningkatkan tingkat kepuasan kualitas pelayanan dan kepercayaan informasi; hal ini menghasilkan peningkatan dalam interaksi pelanggan, berpotensi membantu perusahaan mencapai yang disebut memaksimalkan keuntungan portofolio.

Menurut Gregory (2012) PT XL Axiata ingin memberikan kualitas pelayanan yang baik dari sudut pandang pelanggan, dan diperlukan sebuah sistem yang mampu menghubungkan data dari banyak sumber, termasuk lokasi, CRM, tarif perangkat, dan jaringan Informasi. Menurut Akbar, et al (2010) kualitas pelayanan memiliki pengaruh positif terhadap loyalitas pelanggan dan kepuasan pelanggan adalah variabel yang merupakan mediasi hubungan antara kualitas pelayanan dan loyalitas pelanggan.

Tahun lalu PT XL Axiata Tbk. sukses menggaet pelanggan melampaui target. Operator telekomunikasi ini berhasil mendapatkan 40,1 juta pelanggan hingga akhir 2010 atau tumbuh 27,7\% dibanding 2009 (31,4 juta pelanggan). Sejatinya peningkatan pelanggan ini geregetnya sudah dirasakan sebelumnya. Tak heran XL harus sampai dua kali merevisi targetnya itu. Awalnya, target yang ditetapkan untuk 2010 itu mampu meraih 35 juta pelanggan. Kemudian diubah menjadi 38 atau 39 juta pelanggan. Per Oktober 2010 direvisi lagi menjadi 40 juta pelanggan. Realisasinya, pelanggannya di atas target yang ditetapkan. Memasuki 2011, manajemen XL menargetkan pelanggannya akan tumbuh $11 \%-12 \%$. Berarti di akhir tahun ini, XL optimistis pelanggannya bisa mencapai 44,5-44,9 juta. Memang, XL selalu menargetkan bisa tumbuh di atas industri yang berkisar di 10\%. (Suryadi dan Nugroho, 2011)

Pesatnya perkembangan dunia maya (digital) atau online saat ini sangatlah layak dipertimbangkan sebuah bisnis untuk segera membangun hubungan dengan pelanggan. Selain kesuksesan akan membawa pada perluasan pasar secara lokal, juga berkompeten untuk perluasan pasar pada skala global. Dalam meningkatkan loyalitas, PT. XL pun tidak bisa hanya dengan memperlakukan pelanggan dengan baik saja tetapi juga perlu memberikan pelayanan yang berkualitas tentunya. Pelayanan yang buruk akan menimbulkan masalah sendiri dalam menjalin hubungan dengan pelanggan dan dapat memberikan dampak yang buruk bagi perusahaan itu sendiri. Dalam memberikan pelayanan memang bukanlah hal yang mudah bagi setiap perusahaan. Oleh karena itu, perusahaan tentunya harus bisa memberikan pelayanan yang baik. Dengan memberikan pelayanan yang baik, tentunya pelanggan akan merasa puas. Rasa puas yang tertanam dalam benak pelanggan bisa memberikan pengaruh yang baik terhadap perusahaan. Selain itu, perlu dilakukan pendekatan pada pelanggan dengan memberikan pelayanan yang sesuai harapan pelanggannya, sehingga pelayanan 
yang diberikan pun bisa dirasakan secara maksimal dan memuaskan pelanggan yang dapat menimbulkan rasa loyal.

Perkembangan dunia digital semakin pesat. Ini menuntut adanya keseriusan dan pemahaman pemilik brand untuk lebih jauh terlibat dalam keseharian konsumen. Hal ini sudah disadari berbagai perusahaan di dunia yang melihat potensi dari sarana media sosial dalam membentuk hubungan dan berkomunikasi dengan konsumen. Salah satu perusahaan yang serius dengan manfaat media sosial adalah PT XL Axiata. XL pun kemudian meluncurkan channel media sosialnya, yaitu untuk Facebook XLRame; untuk twitter @XL123, untuk Pinterst Pinterest.com/XL123; dan untuk 8track 8tracks.com/XL123. Menurut Senior VP Marketing Brand Communications PT XL Axiata, Tommy Wattimena, sekarang tren penggunaan customer service dalam melayani keluhan sudah mulai menurun. Dalam sehari ada sekitar 60 ribu keluhan yang disampaikan melalui media sosial. Namun hanya 10 persen yang benar-benar merupakan keluhan yang serius dan perlu penanganan khusus. Media sosial yang dikelola dengan baik dapat menguntungkan perusahaan. Tahun kemarin di bulan November, sentimen negatif pelanggan mencapai 65 persen. Namun tahun ini di bulan yang sama mengalami penurunan. "Sekarang sentimen negatif hanya 25 persen," kata Tommy Wattimena. Selain itu, sosial media juga digunakan untuk memberikan informasi-informasi perusahaan, sehingga pesanpesan perusahaan dapat sampai dengan cepat kepada para konsumen. "Ini merupakan keberhasilan besar XL Axiata dalam memaksimalkan inovasi teknologi dan informasi di media sosial, sehingga mendapatkan apresiasi yang baik dari konsumen," lanjutnya. (Galih dan Wibowo, 2012)

Dalam penelitian ini, observasi dilakukan pada PT XL yang bertempat di Jl. Mega Kuningan Lot E4-7 no. 1, Jakarta 12950, sebagai objek penelitian. PT XL bergerak di bidang telekomunikasi. Mengingat banyaknya pesaing pada dunia bisnis tersebut, maka dibutuhkan suatu metode yang kuat untuk meningkatkan loyalitas pelanggan.

Metode yang dapat digunakan untuk membuat hubungan sedekat mungkin antara perusahaan dengan konsumennya adalah dengan CRM (Customer Relationship Management), yang dengan penggunaan metode ini pelanggan akan dapat merasa lebih dimengerti oleh perusahaan atau bisnis unit tersebut. CRM pada era komputer sekarang ini telah dikembangkan dan ditingkatkan fiturnya menjadi e-CRM (Electronic Customer Relationship Management) yang fungsi CRM tersebut bukan hanya sebuah aplikasi yang digunakan hanya sebagai call center atau help desk tetapi juga digunakan sebagai aplikasi pemasaran dan sebagai penghubung antara perusahaan dengan tiap-tiap pelanggannya.

PT XL sering membuat program baru untuk digunakan para remaja. Oleh karena itu, sebelum produk atau jasa tersebut dihasilkan, sebaiknya perusahaan mengenal, mengetahui, dan menggali hal yang dibutuhkan dan diharapkan dari konsumennya. Strategi yang dapat diterapkan dari pembahasan tersebut adalah dengan menggunakan CRM; dan saat ini penerapan CRM juga dapat melalui teknologi Internet yang disebut e-CRM, yaitu salah satu strategi yang digunakan untuk mengetahui kebutuhan konsumen dan juga untuk menarik, menjaga atau mempertahankan konsumen agar tetap dekat dengan perusahaan. CRM dikatakan berhasil jika perusahaan tersebut sudah mendapatkan customer loyalty terhadap perusahaan. Tujuan penelitian ini adalah untuk menganalisis pengaruh $e-C R M$ dan service quality terhadap customer satisfaction dan dampaknya terhadap customer loyalty pada PT XL.

\section{Tinjauan Pustaka}

Menurut Buttle (2006), Customer Relationship Management adalah pendekatan strategi manajemen dalam upaya menciptakan, mengembangkan, dan mewujudkan hubungan yang saling menguntungkan dengan pelanggan dalam jangka panjang, khususnya terhadap pelanggan potensial, dalam upaya memaksimalkan costumer value (nilai pelanggan) dan corporate profitability. Menurut Barnes (2003), tujuan utama pemasaran tertinggi adalah mencapai tingkat kepuasan pelanggan. Pada kenyataannya, akhir-akhir ini banyak perhatian tercurah pada kepuasan "total", yang implikasinya 
adalah mencapai kepuasan sebagian saja tidaklah cukup untuk membuat pelanggan setia dan kembali lagi. Ketika pelanggan merasa puas terhadap pelayanan yang didapatkan saat proses transaksi dan juga puas terhadap barang atau jasa yang didapatkan, besar kemungkinan mereka akan kembali lagi dan melakukan pembelian-pembelian yang lain. Juga, mereka akan merekomendasikan pada teman-teman dan keluarga tentang perusahaan tersebut dan produk-produknya. Selain itu, kecil kemungkinan mereka berpaling ke pesaing lain. Mempertahankan kepuasan pelanggan dari waktu ke waktu akan membina hubungan yang baik dengan pelanggan. Hal ini dapat meningkatkan keuntungan perusahaan dalam jangka panjang.

Kepuasan pelanggan menunjukkan bahwa terpenuhinya suatu kebutuhan menciptakan suatu kenyamanan bagi pelanggan. Yang memuaskan satu pelanggan mungkin tidak memuaskan pelanggan yang lainnya; kenyataannya, yang dapat memuaskan pelanggan di satu situasi mungkin tidak bisa memuaskan pelanggan yang sama di situasi lain. Dengan demikian, kepuasan pelanggan adalah target yang berubah-ubah karena masing-masing pelanggan memiliki serangkaian kebutuhan pada tingkat yang berbeda-beda. Oleh karena itu, CRM diperlukan untuk menjaga kepuasan pelanggan tersebut.

Menurut Turban, et al (2006), menjalin relasi dengan pelanggan merupakan salah satu aktivitas bisnis yang telah dilakukan oleh berbagai perusahaan dari generasi ke generasi. Bahkan sebelum adanya komputer, perusahaan telah mampu menjalin hubungan dengan baik dengan para pelanggannya. Namun pada pertengahan 1990-an, CRM telah diperkaya oleh berbagai informasi teknologi. Penerapan teknologi dalam CRM merupakan respons terhadap perubahan-perubahan yang ada dalam dunia. Istilah e-CRM mulai digunakan pada pertengahan 1990-an ketika pelanggan mulai menggunakan web browser, Internet, dan touch point elektronik lainnya (email, PDA, call centers). ECRM merupakan pengembangan dari CRM yang dilakukan secara elektronik.

Menurut Chaffey (2009), e-CRM memiliki definisi penggunaan teknologi komunikasi digital untuk memaksimalkan penjualan pada pelanggan dan mendorong penggunaan online service. Menurut Oliver yang dikutip oleh Barnes (2003) kepuasan pelanggan adalah tanggapan pelanggan atas terpenuhinya kebutuhannya. Hal ini berarti penilaian suatu bentuk keistimewaan dari suatu barang dan jasa memberikan tingkat kenyamanan yang terkait dengan pemenuhan kebutuhan melebihi harapan pelanggan. Pelanggan adalah orang-orang yang keputusannya memengaruhi kekayaan perusahaan. Mereka mungkin suatu kelompok yang kompleks dan terdiri dari berbagai lapisan namun harus diketahui dan dilayani untuk menjamin kesejahteraan perusahaan.

Menurut Kotler dan Amstrong (2006) tentang kepuasan konsumen, yaitu: "Customer satisfaction is closely linked to quality. Quality has a direct impact of product performance and customer satisfaction." Artinya, kepuasan konsumen sangat berkaitan erat dengan kualitas. Kualitas memiliki dampak langsung terhadap performa produk dan kepuasan konsumen. Menurut Walker, et al (2006), yaitu: "For marketers, the best measures of quality is customer satisfaction." Artinya, bagi pemasar, ukuran kualitas yang paling baik adalah kepuasan konsumen. Lebih lanjut, menurut Tjiptono (2008): "Dengan memperhatikan kualitas pelayanan kepada konsumen, akan meningkatkan indeks kepuasan kualitas konsumen yang diukur dalam ukuran apapun."

Buttle (2006) menyatakan bahwa pelanggan dalam konteks B2B (business to business) adalah sebuah organisasi perusahaan (produsen atau reseller) atau sebuah institusi (nirlaba atau badan pemerintahan), sedangkan pelanggan dalam konteks B2C (business to customers) adalah konsumen akhir, yakni seorang individu atau sebuah keluarga. Sekalipun demikian ada pula ahli marketing yang menyatakan bahwa istilah pelanggan terutama digunakan untuk menunjukkan pembeli, baik perseorangan atau organisasi yang relatif teratur dan menetap mengadakan transaksi di pasar kepada penjual tertentu.

Beberapa literatur manajemen jasa menyatakan bahwa kepuasan konsumen memengaruhi loyalitas konsumen dan selanjutkan mendatangkan laba atau keuntungan (Hallowell, 1996; Goncalves, 
1998; Zeithaml dan Bitner; 2000; dan Lovelock, 2001). Para peneliti ini mendiskusikan antara kepuasan dan loyalitas. Jadi, membangun loyalitas konsumen adalah salah satu tantangan terbesar bagi industri pelayanan jasa (Bowen dan Chen, 2001).

Loyalitas pelanggan memilik peran dalam sebuah perusahaan. Mempertahankan pelanggan berarti meningkatkan kinerja keuangan dan mempertahankan kelangsungan hidup perusahaan. Hal ini menjadi alasan utama bagi sebuah perusahaan untuk menarik dan mempertahankan pelanggan. Usaha untuk memperoleh pelanggan yang loyal tidak dapat dilakukan sekaligus namun melalui beberapa tahapan, mulai dari mencari pelanggan potensial sampai dengan memperoleh rekan kerja.

Buttle (2006) menjelaskan bahwa CRM meningkatkan performance bisnis dengan meraih kepuasan dan meraih loyalitas pelanggan. Gambar 1 menjelaskan tentang hubungan CRM dengan loyalitas pelanggan.

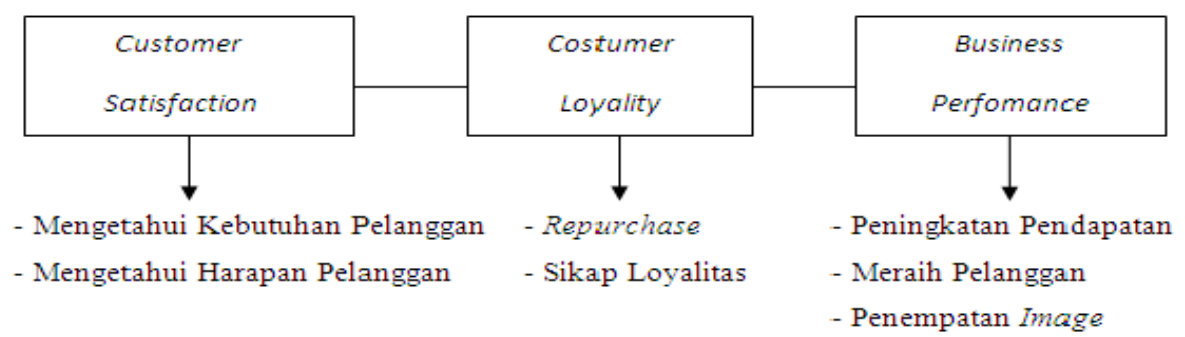

Gambar 1 Hubungan CRM dengan Loyalitas Pelanggan

(Sumber: Buttle, 2006)

Sementara Gambar 2 menunjukkan kerangka berpikir penelitian ini.

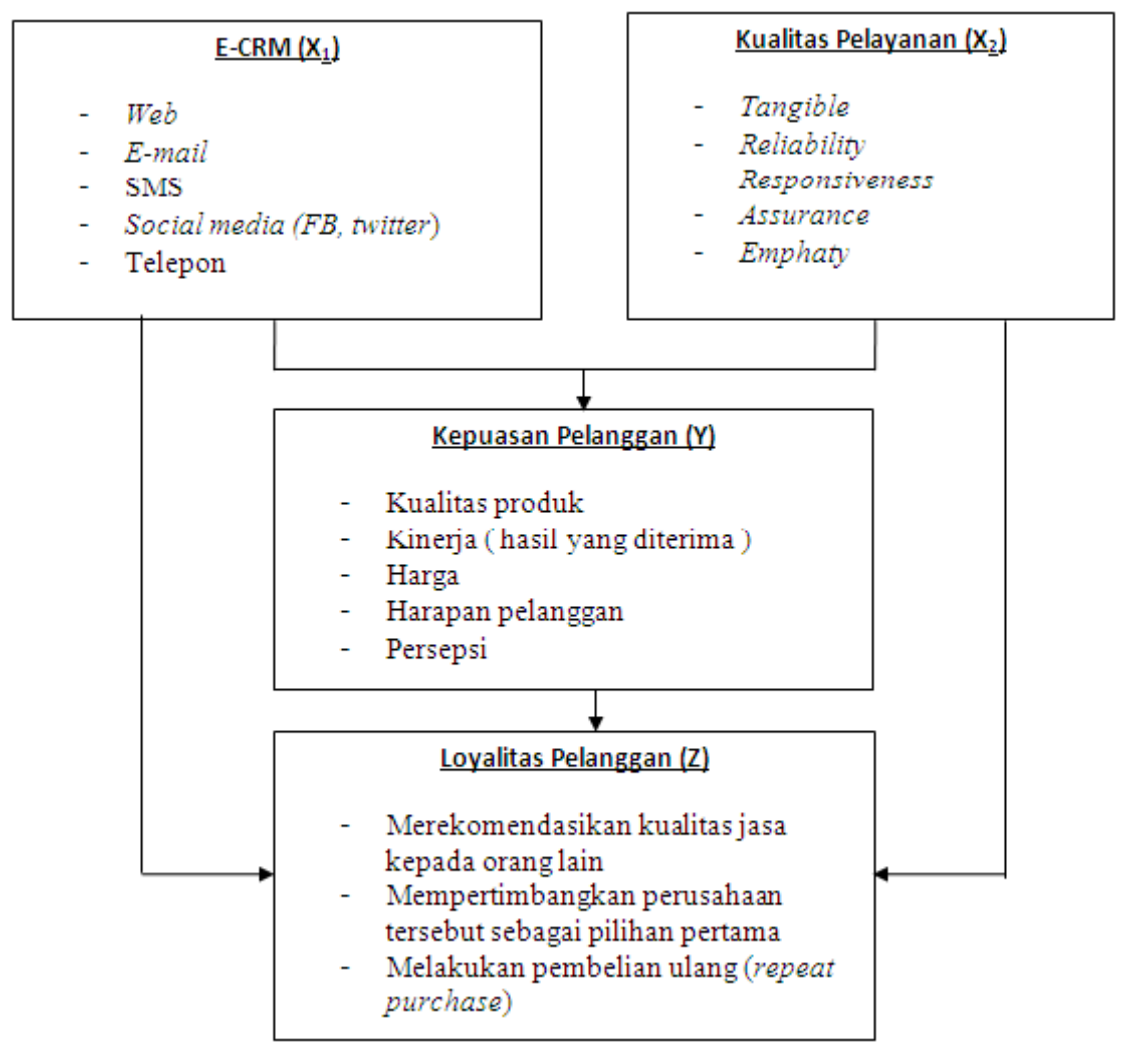

Gambar 2 Kerangka Berpikir 


\section{METODE PENELITIAN}

Penelitian menggunakan penelitian deskriptif yang bersifat asosiatif. Unit analisis pada penelitian adalah individu, yaitu pelanggan XL. Horizon waktu untuk penelitian adalah cross-sectional yang data dari masing-masing responden hanya sekali dikumpulkan dalam rangka menjawab pertanyaan penelitian. Operasional variabel penelitian ditunjukkan pada Tabel 1.

Tabel 1 Tabel Operasional Variabel Penelitian

\begin{tabular}{|c|c|c|c|}
\hline Variabel & Dimensi & Indikator & Skala pengukuran \\
\hline \multirow{5}{*}{$\begin{array}{l}\text { e-CRM } \\
\text { Berhubungan } \\
\text { dengan pelanggan } \\
\text { secara elektronik }\end{array}$} & Web & Mengetahui informasi produk. & \multirow{5}{*}{$\begin{array}{l}\text { Skala Likert } \\
1 \mathrm{sd} 5\end{array}$} \\
\hline & E-mail & Melayani feedback pelanggan. & \\
\hline & SMS & Memberitahu pelanggan info-info. & \\
\hline & $\begin{array}{l}\text { Social media } \\
(\mathrm{FB}, \text { twitter })\end{array}$ & Promosi melalui jejaring sosial. & \\
\hline & Telepon & Melayani keluhan dan saran via telepon. & \\
\hline \multirow[t]{5}{*}{$\begin{array}{l}\text { Kualitas Pelayanan } \\
\text { Pelayanan yang } \\
\text { sesuai persepsi } \\
\text { pelanggan }\end{array}$} & Tangible & $\begin{array}{l}\text { Penampilan fisik dan desain baik tata } \\
\text { letak interior, eksterior, maupun } \\
\text { penampilan fisik dari personel penyedia } \\
\text { jasa. }\end{array}$ & \multirow{3}{*}{ Skala Likert 1 sd 5} \\
\hline & Reliability & $\begin{array}{l}\text { Kemampuan memberikan pelayanan yang } \\
\text { akurat, memuaskan, tepat dan teroercaya } \\
\text { sebagaimana dijanjikan. }\end{array}$ & \\
\hline & Responsiveness & $\begin{array}{l}\text { Pelayanan staff yang tepat, cepat dan } \\
\text { tanggap. }\end{array}$ & \\
\hline & Assurance & $\begin{array}{l}\text { Membangkitkan rasa percaya dan } \\
\text { keyakinan diri bagi pelanggan, bebas dari } \\
\text { bahaya, resiko atau keraguan. }\end{array}$ & \multirow{2}{*}{ Ordinal $\rightarrow$ Interval } \\
\hline & Emphaty & $\begin{array}{l}\text { Sikap peduli dan pengertian, } \\
\text { memperlakukan pelanggan sebagai } \\
\text { individu yang special. }\end{array}$ & \\
\hline \multirow{5}{*}{$\begin{array}{l}\text { Kepuasan } \\
\text { Pelanggan } \\
\text { Harapan pelanggan } \\
\text { dengan pelayanan } \\
\text { yang diterima }\end{array}$} & Kualitas produk & $\begin{array}{l}\text { Harus memiliki produk berkualitas dan } \\
\text { layanan yang baik. }\end{array}$ & \multirow{5}{*}{$\begin{array}{l}\text { Skala Likert } \\
1 \mathrm{sd} 5\end{array}$} \\
\hline & $\begin{array}{l}\text { Kinerja ( hasil } \\
\text { yang diterima ) }\end{array}$ & $\begin{array}{l}\text { Produk dan jasa sesuai yang pelanggan } \\
\text { pikirkan }\end{array}$ & \\
\hline & $\begin{array}{l}\text { Harapan } \\
\text { pelanggan }\end{array}$ & $\begin{array}{l}\text { Perbandingan antara harapan pelanggan } \\
\text { dengan kinerja yang ada. }\end{array}$ & \\
\hline & Persepsi & $\begin{array}{l}\text { Tingkat kemudahan pelanggan dalam } \\
\text { mengoperasikan dan mendapatkan produk } \\
\text { perusahaan yang ditawarkan. }\end{array}$ & \\
\hline & Harga & Harga sensitif bagi pelanggan & \\
\hline \multirow{3}{*}{$\begin{array}{l}\text { Loyalitas } \\
\text { pelanggan } \\
\text { Bagaimana perilaku } \\
\text { pelanggan dalam } \\
\text { melakukan } \\
\text { pembelian kembali }\end{array}$} & Recommendation & $\begin{array}{l}\text { Merekomendasikan produk kepada orang } \\
\text { lain. }\end{array}$ & \multirow{3}{*}{$\begin{array}{l}\text { Skala Likert } \\
1 \mathrm{sd} 5\end{array}$} \\
\hline & Refuse & $\begin{array}{l}\text { Mempertimbangkan produk tersebut } \\
\text { sebagai pilihan pertama. Menolak pilihan } \\
\text { lain. }\end{array}$ & \\
\hline & Repeat purchase & Melakukan pembelian ulang. & \\
\hline
\end{tabular}

Pengumpulan data dan informasi yang diperlukan dalam penelitian menggunakan kuesioner. Populasi dalam penelitian adalah pelanggan XL Jakarta Barat sebanyak tiga juta pelanggan dan dengan rumus Slovin diperoleh sampel sebanyak 100 orang responden. Teknik sampling yang digunakan adalah simple random sampling. Prinsip pemilihan dalam pengambilan sampel dalam desain ini adalah setiap elemen dalam populasi mempunyai kesempatan yang sama untuk dipilih. 
Analisis Jalur digunakan untuk menganalisis data penelitian dengan mencari hubungan sebab akibat yang terjadi pada regresi berganda jika variabel bebas memengaruhi variabel terikat tidak hanya secara langsung tetapi juga secara tidak langsung.

\section{HASIL DAN PEMBAHASAN}

Sebelum melanjutkan analisis analisis korelasi antarvariabel X1, X2, dan Y, akan ditampilkan lebih dahulu struktur hubungan kausal antara variabel inovasi produk $\left(\mathrm{X}_{1}\right), \mathrm{CRM}\left(\mathrm{X}_{2}\right)$, kepuasan pelanggan (Y), dan loyalitas pelanggan (Z) pada Gambar 3 berikut.

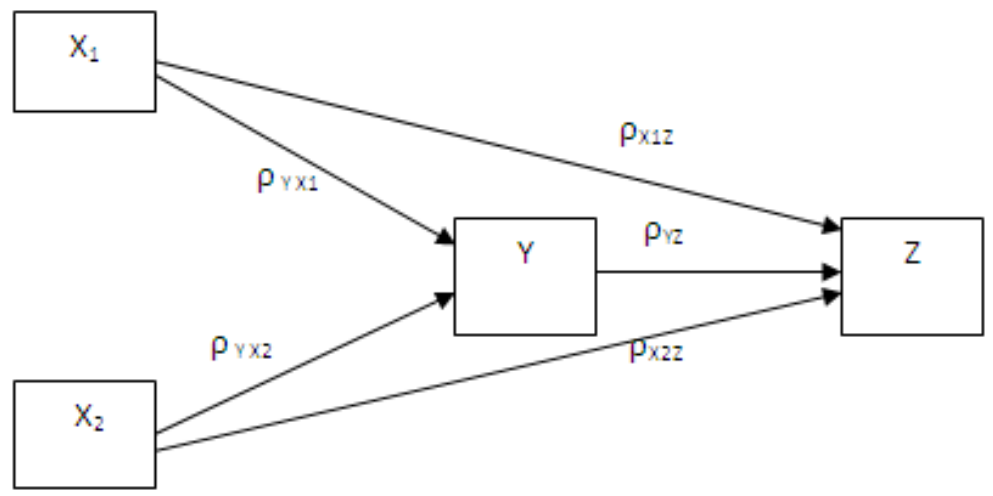

Gambar 3 Struktur Hubungan X1, X2, Y, dan Z secara Lengkap

Dalam analisis pengaruh e-CRM $\left(\mathrm{X}_{1}\right)$ dan kualitas pelayanan $\left(\mathrm{X}_{2}\right)$ terhadap kepuasan pelanggan $(\mathrm{Y})$ akan digambarkan sebuah model yang selanjutnya disebut dengan substruktur 1 . Untuk mengetahui korelasi antarvariabel $\mathrm{X}_{1}(\mathrm{e}-\mathrm{CRM}), \mathrm{X}_{2}$ (kualitas pelayanan), dan $\mathrm{Y}$ (kepuasan pelanggan) digunakan program SPSS dengan hasil perhitungan terangkum pada Tabel 2 sebagai berikut.

Tabel 2 Sifat Hubungan Korelasi X1, X2, Y

\begin{tabular}{ccc}
\hline Hubungan antara & Korelasi & Sifat hubungan \\
\hline $\mathrm{X}_{1}$ dengan $\mathrm{X}_{2}$ & 0,154 & Sangat rendah, searah \\
$\mathrm{X}_{1}$ dengan $\mathrm{Y}$ & 0,361 & Rendah, searah \\
$\mathrm{X}_{2}$ dengan $\mathrm{Y}$ & 0,378 & Rendah, searah \\
\hline
\end{tabular}

(Sumber: Hasil Pengolahan Data, 2012)

Sementara Tabel 3 berikut merupakan Anova Substruktur 1.

Tabel 3 Anova $^{\mathrm{b}}$ Substruktur 1

\begin{tabular}{llccccc}
\hline & Model & Sum of Squares & df & Mean Square & F & Sig. \\
\hline 1 & Regression & 5.029 & 2 & 2.514 & 15.019 & $.000^{\mathrm{a}}$ \\
Residual & 16.239 & 97 & .167 & & \\
Total & 21.268 & 99 & & & \\
\hline
\end{tabular}

a. Predictors (Constant): kualitas pelayanan, e-CRM

b. Dependent Variable: kepuasan pelanggan

(Sumber: Hasil Pengolahan Data, 2012) 
Tabel 4 berikut adalah model summary substruktur 1.

Tabel 4 Model Summary Substruktur 1

\begin{tabular}{lccrr} 
Model & R & R Square & $\begin{array}{c}\text { Adjusted R } \\
\text { Square }\end{array}$ & $\begin{array}{l}\text { Std. Error of } \\
\text { the Estimate }\end{array}$ \\
\hline 1 & $.486^{\text {a }}$ & .236 & .221 & .40916 \\
\hline a. Predictors (Constant): kualitas pelayanan, e-CRM & \\
b. Dependent Variable: kepuasan pelanggan &
\end{tabular}

(Sumber: Hasil Pengolahan Data, 2012)

Dari hasil uji signifikansi pada tabel 5 dengan $\alpha=0,05$, didapat nilai sig sebesar 0,000 maka nilai sig lebih kecil dari $\alpha$ (sig $\leq \alpha)$, yaitu $0,000 \leq 0,05$. Hal tersebut menunjukan bahwa $\mathrm{H} 0$ ditolak dan Ha diterima, yang artinya koefisien regresi adalah signifikan. Variabel X1 dan X2 berpengaruh secara simultan dan signifikan terhadap variabel Y. Oleh karena itu, pengujian secara individual dapat dilakukan.

Tabel 5 Koefisien ${ }^{\text {a }}$ Substruktur 1

\begin{tabular}{|c|c|c|c|c|c|c|}
\hline \multirow{2}{*}{\multicolumn{2}{|c|}{ Model }} & \multicolumn{2}{|c|}{$\begin{array}{c}\text { Unstandardized } \\
\text { Coefficients }\end{array}$} & \multirow{2}{*}{$\begin{array}{c}\begin{array}{c}\text { Standardized } \\
\text { Coefficients }\end{array} \\
\text { Beta } \\
\end{array}$} & \multirow[b]{2}{*}{$\mathbf{t}$} & \multirow[b]{2}{*}{ Sig. } \\
\hline & & B & Std. Error & & & \\
\hline \multirow[t]{3}{*}{1} & (Constant) & 1.180 & .354 & & 3.333 & .001 \\
\hline & eCRM & .270 & .078 & .310 & 3.453 & .001 \\
\hline & kualitas_pelayanan & .297 & .081 & .330 & 3.675 & .000 \\
\hline
\end{tabular}

a. Dependent Variable: kepuasan pelanggan

(Sumber: Hasil Pengolahan Data, 2012) berikut:

Berdasarkan hasil analisis jalur substruktur 1, persamaan yang diperoleh adalah sebagai

$\mathrm{Y}=\rho \mathrm{YX} 1+\rho \mathrm{YX} 2+\varepsilon 1$

$\mathrm{Y}=0,310 \mathrm{X} 1+0,330 \mathrm{X} 2+0,874 \varepsilon 1$

Sedangkan hasil substruktur 1 seperti pada Gambar 4.

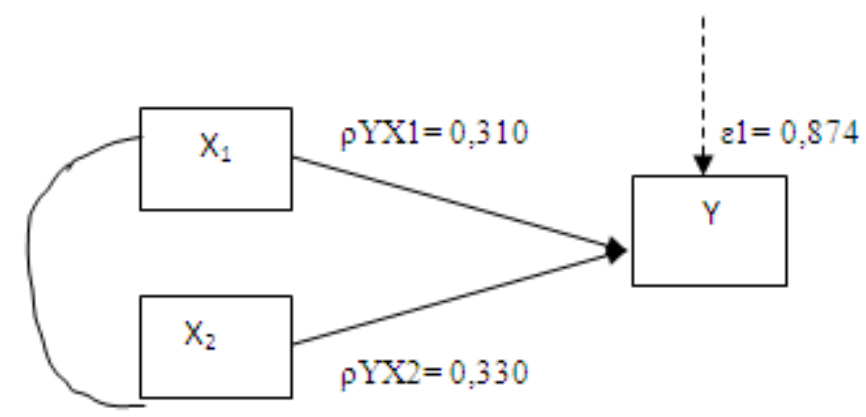

Gambar 4 Hasil Substruktur 1 
Selanjutnya akan dibahas analisis implementasi (x1), (x2), (y), dan (z). Tabel 6 menunjukkan sifat hubungan korelasi X1, X2, Y, dan Z.

Tabel 6 Sifat hubungan Korelasi X1, X2, Y, dan Z

\begin{tabular}{ccc}
\hline Hubungan antara & Korelasi & Sifat hubungan \\
\hline $\mathrm{X}_{1}$ dengan $\mathrm{Z}$ & 0,156 & Sangat rendah dan searah \\
$\mathrm{X}_{2}$ dengan $\mathrm{Z}$ & 0,100 & Sangat rendah dan searah \\
$\mathrm{Y}$ dengan $\mathrm{Z}$ & 0,424 & Cukup kuat dan searah \\
\hline
\end{tabular}

(Sumber: Hasil Pengolahan Data, 2012)

Kemudian untuk melihat pengaruh X1, X2, Y terhadap Z dapat dibantu dengan menggunakan program SPSS yang menghasilkan output seperti pada Tabel 7.

Tabel 7 Anova $^{\mathrm{b}}$ - Substruktur 2

\begin{tabular}{|c|c|c|c|c|c|c|}
\hline Model & & Sum of Squares & df & Mean Square & $\mathbf{F}$ & Sig. \\
\hline \multirow[t]{3}{*}{1} & Regression & 10.972 & 3 & 3.657 & 7.216 & $.000^{\mathrm{a}}$ \\
\hline & Residual & 48.653 & 96 & .507 & & \\
\hline & Total & 59.625 & 99 & & & \\
\hline
\end{tabular}

a. Predictors (Constant): kepuasan pelanggan, e-CRM, kualitas pelayanan

b. Dependent Variable: loyalitas pelanggan

(Sumber: Hasil Pengolahan Data, 2012)

Nilai Sig $=0,000(<0,05)$ maka Ho ditolak dan Ha diterima, sehingga dapat ditarik kesimpulan bahwa variabel e-CRM $\left(\mathrm{X}_{1}\right)$ dan kualitas pelayanan $\left(\mathrm{X}_{2}\right)$ dan kepuasan pelanggan $(\mathrm{Y})$ berpengaruh secara simultan dan signifikan terhadap variabel loyalitas pelanggan (Z). Oleh karena itu, pengujian secara individual dapat dilakukan atau dilanjutkan. Tabel 8 dan Tabel 9 berikut berturutturut menunjukkan koefisien substruktur 2 dan model summary substruktur 2.

Tabel 8 Coefficients ${ }^{\mathrm{a}}$ Substruktur 2

\begin{tabular}{|c|c|c|c|c|c|c|}
\hline \multirow{2}{*}{\multicolumn{2}{|c|}{ Model }} & \multicolumn{2}{|c|}{ Unstandardized Coefficients } & \multirow{2}{*}{$\begin{array}{c}\text { Standardized Coefficients } \\
\text { Beta }\end{array}$} & \multirow[b]{2}{*}{$\mathbf{t}$} & \multirow[b]{2}{*}{ Sig. } \\
\hline & & B & Std. Error & & & \\
\hline 1 & (Constant) & 1.164 & .650 & & 1.790 & .077 \\
\hline & eCRM & .007 & .144 & .005 & .052 & .959 \\
\hline & kualitas_pelayanan & -.106 & .150 & -.070 & -.707 & .481 \\
\hline & kepuasan_pelanggan & .751 & .177 & .449 & 4.253 & .000 \\
\hline
\end{tabular}

a. Dependent Variable: loyalitas pelanggan

(Sumber: Hasil Pengolahan Data, 2012)

Tabel 9 Model Summary ${ }^{\mathrm{b}}$ Sub-Struktur 2

\begin{tabular}{lcccr}
\hline Model & R & R Square & Adjusted R Square & Std. Error of the Estimate \\
\hline 1 & $.429^{\text {a }}$ & .184 & .159 & .71190 \\
\hline a. Predictors (Constant): kepuasan pelanggan, e-CRM, kualitas pelayanan & \\
b. Dependent Variable: loyalitas pelanggan & &
\end{tabular}

(Sumber: Hasil Pengolahan Data, 2012) 
berikut:

Berdasarkan hasil analisis jalur substruktur 2, persamaan yang diperoleh adalah sebagai

$Z=\rho Z X 1+\rho Z X 2+\rho Z Y+\varepsilon_{2}$

$Z=0,005 X 1+-0,070 X 2+0,449 Y+0,903 \varepsilon_{2}$

Sedangkan hasil substruktur 2 seperti pada Gambar 5.

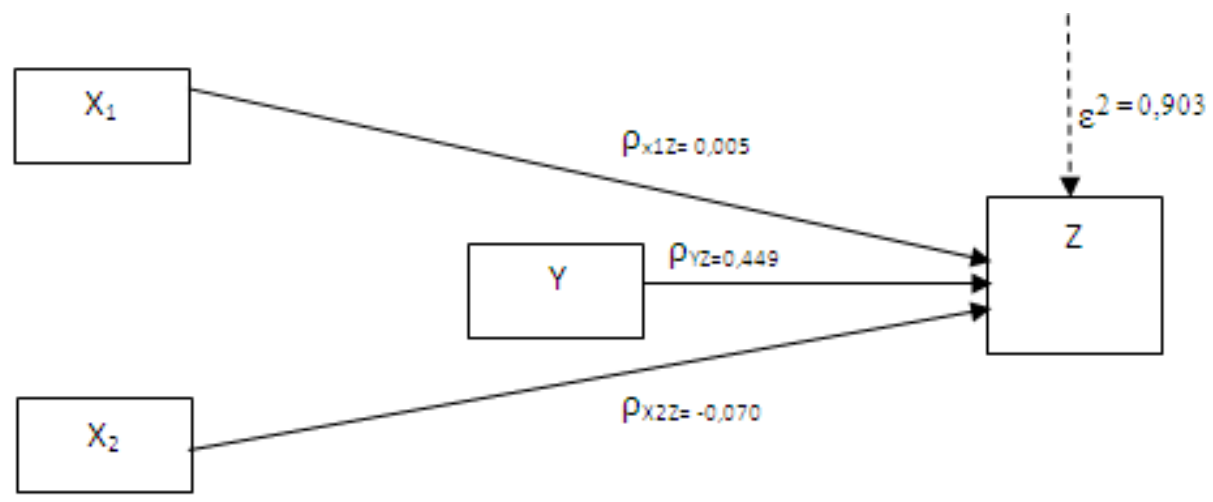

Gambar 5. Hasil Sub-struktur 2

Untuk lebih jelasnya, Tabel 10 merangkum seluruh hasil koefesien jalur serta pengaruh tidak langsung dan pengaruh total.

Tabel 10 Analisis Jalur X1, X2 terhadap Y dan Dampaknya terhadap Z

\begin{tabular}{ccccc}
\hline & Koefisien & \multicolumn{3}{c}{ Pengaruh } \\
\cline { 3 - 5 } Variabel & Jalur & Langsung & Tidak Langsung Melalui Y & Total \\
\hline$X_{1} \rightarrow Y$ & 0,310 & 0,310 & - & 0,310 \\
$X_{2} \rightarrow Y$ & 0,330 & 0,330 & - & 0,330 \\
$X_{1} \rightarrow Z$ & 0,005 & - & $0,310 \times 0,449=0,139$ & 0,144 \\
$X_{2} \rightarrow Z$ & $-0,070$ & - & $0,330 \times 0,449=0,148$ & 0,078 \\
$Y \rightarrow Z$ & 0,449 & 0,449 & - & 0,449 \\
$\varepsilon 1$ & 0,874 & 0,874 & - & 0,874 \\
$\varepsilon 2$ & 0,903 & 0,903 & - & 0,903 \\
\hline
\end{tabular}

(Sumber: Hasil Pengolahan Data, 2012)

\section{SIMPULAN}

Berdasarkan hasil analisis dan pembahasan, penelitian menyimpulkan sebagai berikut. Pertama, secara simultan e-CRM dan Service Quality memiliki pengaruh terhadap Customer Satisfaction; secara parsial e-CRM, Service Quality memiliki pengaruh terhadap Customer Satisfaction. Kedua, secara parsial Customer Satisfaction memiliki pengaruh terhadap Customer Loyalty. Ketiga, secara simultan e-CRM dan Service Quality tidak memiliki pengaruh terhadap Customer Loyalty; secara parsial e-CRM, Service Quality tidak memiliki pengaruh terhadap Customer Loyalty. Keempat, secara simultan e-CRM dan Service Quality memiliki pengaruh terhadap Customer Loyalty tetapi harus melalui Customer Satisfaction. 
Sedangkan saran penelitian kepada PT XL adalah sebagai berikut. PT XL disarankan untuk membuat program baru e-CRM yang dapat memenuhi kebutuhan pelanggan saat ini dan direspon dengan cepat dan tepat. Jika konsumen merasa kebutuhannya terpenuhi, otomatis tercipta kepuasan yang akan memberi pengaruh yang sangat tinggi terhadap loyalitas pelanggan XL. PT XL disarankan untuk memperbanyak kegiatan yang dapat menggarap pangsa pasar remaja dan membuat event kegiatan ke sekolah-sekolah dan memberikan promosi menarik. PT XL memperbanyak tenaga kerja operator customer service agar dapat menjawab telepon yang masuk untuk menyampaikan keluhan. Tenaga kerja tersebut harus diberikan pelatihan secara teratur agar memahami segala macam solusi supaya konsumen tidak menunggu lama di telepon. PT XL memberikan product knowledge secara rutin kepada karyawan di XL center. Sehingga konsumen mendapat informasi dengan cepat dan tepat. Konsumen dipermudah untuk membeli produk tersebut dengan cara menawarkan produk untuk diantar ke rumah dan tidak dikenakan biaya agar konsumen tersebut tetap mau membeli dan dapat diperoleh dengan mudah. PT XL mempertahankan produk layanan dan fitur agar konsumen tetap mau menggunakan produk tersebut. Tarif sms, telepon, dan Internet dipermurah dan sinyal diperkuat dengan mendirikan pemancar sinyal di wilayah pedalaman untuk menciptakan kepuasan pelanggan. Karena terlihat bahwa hubungan antara kepuasan pelanggan dan loyalitas pelanggan sangat kuat. Jadi dengan menciptakan kepuasan pelanggan yang tinggi, hal itu dapat meningkatkan dan memengaruhi loyalitas pelanggan XL.

\section{DAFTAR PUSTAKA}

Akbar, S., Som, A. P. M., Wadood, F., Alzaidiyeen, N. J. (2010). Revitalization of Service Quality to Gain Customer Satisfaction and Loyalty. International Journal of Business and Management. Vol 5, Edisi 6 (Jun 2010), pp. 113-122.

Barnes, J. G. (2003). Secrets of Customer Relationship Management. Yogyakarta: ANDI.

Bowen, J. T., and Chen, S. (2001). The Relationship Between Customer Loyalty and Customer Satisfaction. International Journal of Contemporary Hospitality Management. No.13/5, pp. 213-217.

Buttle, F. (2006). Costumer Relationship Management Concept and Tools. Buttlerworth-Heinemann. Jakarta: Erlangga.

Chaffey, Dave. (2009). E-Business and E-Commerce Management. England: Pearson Education.

Galih, B., dan Wibowo, T. A. (2012, 15 November). Media Sosial Bantu XL Kurangi Keluhan Pelanggan. Diakses 13 November 2013 dari http://m.bola.viva.co.id/news/read/367567media-sosial-bantu-xl-kurangi-keluhan-pelanggan

Gregory, N. (2012). Aito and Anritsu improve customer experience for PT XL Axiata; State-of-the-art customer experience analytics provides the big picture of customer experience for leading Indonesian mobile operator. Normans Media Ltd.

Hallowell, R. (1996). The Relationship of Customer Satisfaction, Customer Loyalty, and Profitability: an Empirical Study. International Journal of Service Industry Management. V Vol.7, No.4, pp.27-42.

Kotler, P., and Amstrong, G. (2006). Prinsip-prinsip Pemasaran (Terjemahan). Jilid pertama. Edisi ke dua belas. Jakarta: Erlangga. 
Lai, Shu-Fang; Hsiao, Ying-Chien; Yang, Yi-Feng; Huang, Yuan-Chih; Lee, I-Chao. (2009). The Mediating Influence of Service Quality Satisfaction and Information Trust on the e-CRM Process Model: An Empirical Bank Marketing Research. Journal of American Academy of Business, Cambridge. Vol 15, Edisi 1 (Sep 2009), pp. 243-253.

Lovelock, C. H. (2001). Services Mareketing; People, Technology, Stratrgy. Fourth Edition (International Edition). USA: Prentice Hall.

Suryadi, D. dan Nugroho, S. A., Amanayanti, E. M. (2011, 2 Februari). XL Axiata: Tumbuh di Atas Rata-rata Industrinya. Diakses 13 November 2013 dari http://swa.co.id/sajian-utama/xlaxiata-tumbuh-di-atas-rata-rata-industrinya $?$ mobile $=$ on

Tjiptono, F. (2008). Strategi Pemasaran. Edisi 3. Yogyakarta: Andi.

Turban, E., King, D., Viehland, D., and Lee, J. (2006). Electronic Commerce 2006: A Managerial Persperctive. Upper Saddle River, New Jersey: Prentice Hall.

Walker, R. H., Johnson, L.W., and Leonard, S. (2006). Re-thinking the conceptualization of customer value and service quality within the service-profit chain. Managing Service Quality. 16(1), pp. 23-36. 